\title{
Yttrium-90 Radioembolization for Hepatocellular Carcinoma: Virtual Tumor Absorbed Dose as a Predictor of Complete Response
}

\author{
HYO-CHEOL KIM ${ }^{1}$, JIN WOO CHOI ${ }^{1}$, MYUNGSU LEE ${ }^{1}$, \\ YOON JUN KIM ${ }^{2}$, JIN CHUL PAENG ${ }^{3}$ and JIN WOOK CHUNG ${ }^{1}$ \\ ${ }^{1}$ Department of Radiology, Seoul National University Hospital, \\ Seoul National University College of Medicine, Seoul, Republic of Korea; \\ ${ }^{2}$ Department of Internal Medicine, Seoul National University Hospital, \\ Seoul National University College of Medicine, Seoul, Republic of Korea; \\ ${ }^{3}$ Department of Nuclear Medicine, Seoul National University Hospital, \\ Seoul National University College of Medicine, Seoul, Republic of Korea
}

\begin{abstract}
Background/Aim: To evaluate the impact of virtual tumor absorbed dose (VTAD) on tumor response in patients with hepatocellular carcinoma (HCC) treated with yttrium-90 radioembolization. Patients and Methods: The institutional review board approved this retrospective single center study, which comprised 100 patients with nodular HCC who underwent yttrium-90 radioembolization between November 2015 and December 2019. The $v T A D$ was calculated assuming that all infused microspheres were distributed only in the tumor. The ability of mean absorbed dose ( $m A D)$ and $v T A D$ in predicting complete response were evaluated by receiver operating characteristic (ROC) curve analyses. Results: The $m A D$ was $263.9 \mathrm{~Gy} \pm 125.8$, and the mean $v T A D$ was $2005.8 \mathrm{~Gy} \pm 2348.9$. In terms of tumor response, 63 patients had complete response, 25 partial response, and 12 stable disease. For predicting complete response, ROC curve analyses revealed that the area under the curve $(A U C)$ value of the $\triangle T A D$ was significantly higher $(p<0.001)$ than that of the $m A D$. Multivariate analysis revealed that Child-Pugh class A5, unilobar disease, and $v T A D$ (>952 Gy) were significant factors in predicting complete response. Conclusion: High vTAD (>952 Gy) plays a significant role in complete response in patients with nodular HCC.
\end{abstract}

This article is freely accessible online.

Correspondence to: Hyo-Cheol Kim, MD, Department of Radiology, Seoul National University Hospital, \#101 Daehak-ro, Jongno-gu, Seoul, 03080, Republic of Korea. Tel: +82 220722584, Fax: +82 27436385, e-mail: angiointervention@gmail.com

Key Words: Hepatocellular carcinoma, radioembolization, tumor absorbed dose.
Radioembolization with yttrium-90 microspheres is a potent intra-arterial therapy for hepatocellular carcinoma (HCC). Compared to chemoembolization, radioembolization provides longer time-to-progression and maintains higher quality of life $(1,2)$. Although it is more expensive than chemoembolization and it is minimally covered by health insurance in many Asian countries, radioembolization could be recommended to patients with a bulky tumor and/or portal vein invasion, based on the Asia-Pacific guidelines (3). Thus, radioembolization is recommended for patients with large tumors, in anticipation of a complete tumor response without severe postembolization syndrome.

The current dosimetry of glass microspheres recommended by the manufacturer is $80 \sim 150 \mathrm{~Gy}$ of the mean absorbed dose (mAD) to the target tissue, assuming that the radioactive microspheres are evenly distributed throughout the target tissue. In a study of selected patients (Child-Pugh class A, unilobar disease, sufficient hepatic reserve), however, boosted radioembolization ( $\mathrm{mAD}$ to the target tissue $>150 \mathrm{~Gy}$ ) was well tolerated and had prolonged overall survival (4). In the case of radiation segmentectomy for small HCC, the mAD to the treated tissue is commonly more than 250 300 Gy $(5,6)$. Based on these clinical experiences, personalized dosimetry incorporated with macroaggregated albumin (MAA) single photon emission computed tomography/computed tomography (SPECT/CT) has been attempted with anticipation of a high tumor absorbed dose (TAD) $(7,8)$. A recent prospective study showed that the personalized dosimetry group had a better tumor response and longer survival than the standard dosimetry group (9).

Given the hypervascularity of HCC, the administered radioactive microspheres are preferentially delivered to the $\mathrm{HCC}$, and TAD would be proportional to the radiation activity 


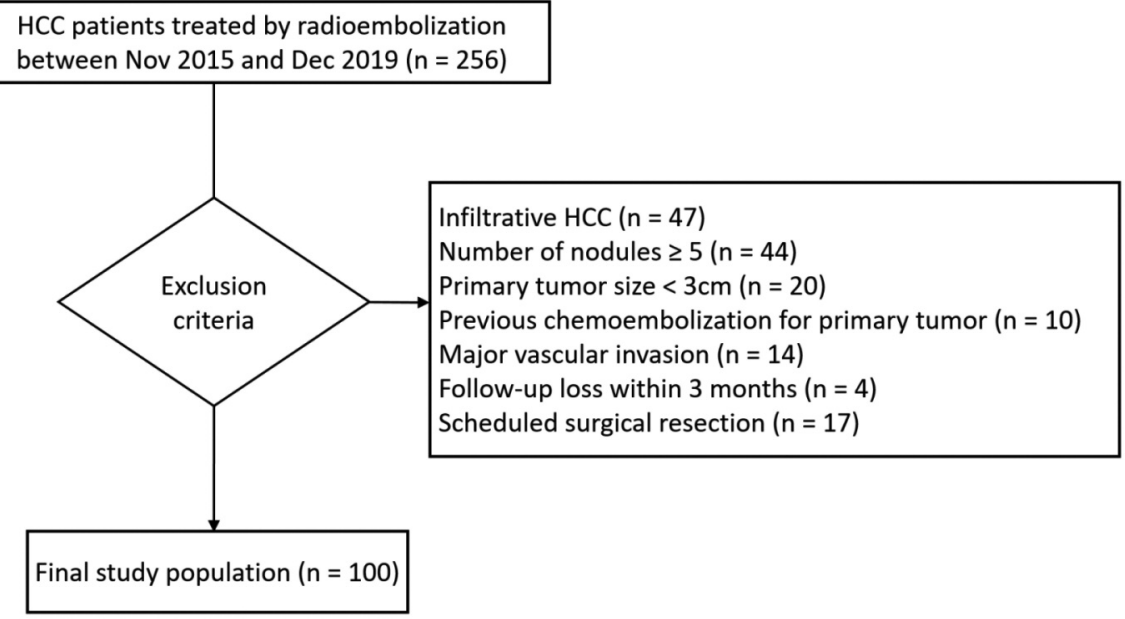

Figure 1. Flow diagram of the study sample.

administered. Thus, the present authors developed two hypotheses: first, virtual tumor absorbed dose (vTAD) can be simply calculated assuming that all infused radioactive microspheres are deposited in the tumor; second, high vTAD may be a good indicator of complete tumor response after radioembolization. Therefore, the purpose of this study was to evaluate the impact of vTAD on tumor response in patients with HCC treated with radioembolization.

\section{Patients and Methods}

Patients. This single center retrospective study was approved by the institutional review board, and informed consent was waived. From November 2015 to December 2019, 256 patients with HCC underwent yttrium-90 radioembolization using glass microspheres (TheraSphere; Boston Scientific, Marlborough, MA, USA). Inclusion criteria were: 1) nodular HCC, 2) four or fewer tumors, 3) $3 \mathrm{~cm}$ or larger in size, 4) no major vascular invasion, 5) no previous chemoembolization, ablation therapy, and systemic therapy (sorafenib) for primary target tumor, and 6) at least three-month imaging follow-up. Exclusion criteria were: 1) infiltrative HCC, 2) five or more tumors, 3 ) less than $3 \mathrm{~cm}$ in size, 4) major vascular invasion, 5) previous chemoembolization, ablation therapy, and systemic therapy (sorafenib) for primary target tumor, 6) scheduled surgical resection after radioembolization, and 7) follow-up loss within three months (Figure 1). Among the 256 patients, 100 met the inclusion and exclusion criteria. Twenty of the 100 patients have been previously reported (10). This prior article dealt with the feasibility of boosted radioembolization for $\mathrm{HCC}$, whereas the present paper deals with the relationship between VTAD and tumor response after radioembolization for HCC.

One hundred patients [84 men and 16 women; mean age $64.6 \pm 12.2$ years (range $=33-89$ years) $]$ comprised this study population (Figure 1). The demographic characteristics of this study population are summarized in Table I. The mean primary tumor size was $7.7 \mathrm{~cm} \pm 3.6$. Sixty-eight patients had a single tumor and 32 patients had multiple tumors. The mean total radiation activity administered was $4.24 \mathrm{GBq} \pm 1.94$ (median $4.04 \mathrm{GBq}$; range $=0.62$ $10.35 \mathrm{GBq}$ ). The mean mAD was $263.9 \mathrm{~Gy} \pm 125.8$ (median 239.5 Gy; range $=74.0-700.2 \mathrm{~Gy})$. The mean vTAD was $2005.8 \mathrm{~Gy} \pm$ 2348.9 (median 1311.1 Gy; range=105.2-12015.0 Gy).

Yttrium-90 radioembolization. Two interventional radiologists (H.C.K. with 14 years of experience in interventional oncology, M.L. with nine years of experience) performed all the procedures. In the early study period (November 2015-June 2016), radioembolization was performed with standard dosimetry (mAD of 100 150 Gy). In the late study period (July 2016-December 2019), boosted radioembolization ( $\mathrm{mAD}>150 \mathrm{~Gy}$ ) had been attempted as long as it was applicable. If at least two segments of normal liver could be saved from irradiation and estimated lung dose was less than $30 \mathrm{~Gy}$, boosted radioembolization with selective catheterization was performed (mAD of 200 360 Gy). The detailed protocol was described in previous studies (10-12). Follow-up imaging studies (contrast-enhanced CT or magnetic resonance imaging) were commonly obtained one month after radioembolization and every two to three months thereafter.

Analysis. Two radiologists (H.C.K., J.W. Choi with four years of experience in interventional oncology) retrospectively reviewed the imaging studies independently, and disagreement was resolved by consensus. Tumor response was assessed by mRECIST (13). The primary target tumor was defined as all tumors present at the radioembolization (maximum tumor number was four). Complete response was defined as complete loss of tumoral enhancement of the primary target tumor in the arterial phase of any follow-up cross-sectional images (i.e., best tumor response).

Total liver volume, treated liver volume, and total tumor volume were measured by volume analysis software (IntelliSpace Portal, version 7; Philips, Andover, MA, USA). The dose calculation was based on the Medical Internal Radiation Dose (MIRD) method recommended by the manufacturer of glass radioactive microspheres. Assuming that all infused microspheres were evenly 
Table I. Baseline characteristics of 100 patients with hepatocellular carcinoma.

\begin{tabular}{|c|c|}
\hline \multicolumn{2}{|l|}{ Gender } \\
\hline Male & 84 \\
\hline Female & 16 \\
\hline Age, mean \pm SD (year) & $64.6 \pm 12.2$ \\
\hline \multicolumn{2}{|l|}{ Etiology } \\
\hline HBV & 74 \\
\hline $\mathrm{HCV}$ & 9 \\
\hline $\mathrm{HBV}$ and $\mathrm{HCV}$ & 3 \\
\hline Alcohol & 2 \\
\hline Cryptogenic & 12 \\
\hline Albumin, mean $\pm \mathrm{SD}(\mathrm{g} / \mathrm{dl})$ & $4.0 \pm 0.4$ \\
\hline Total bilirubin, mean $\pm \mathrm{SD}(\mathrm{mg} / \mathrm{dl})$ & $0.6 \pm 0.3$ \\
\hline Prothrombin time, mean \pm SD (INR) & $1.03 \pm 0.09$ \\
\hline Platelet, mean \pm SD (billion/l) & $195.6 \pm 90.2$ \\
\hline AST & $45.9 \pm 33.3$ \\
\hline ALT & $39.5 \pm 29.0$ \\
\hline \multicolumn{2}{|l|}{ BCLC stage $\neq$} \\
\hline A & 62 \\
\hline $\mathrm{B}$ & 29 \\
\hline $\mathrm{C}$ & 9 \\
\hline \multicolumn{2}{|l|}{ ECOG } \\
\hline 0 & 91 \\
\hline 1 & 9 \\
\hline \multicolumn{2}{|l|}{ Child-Pugh class } \\
\hline A5 & 84 \\
\hline A6 & 15 \\
\hline B8 & 1 \\
\hline \multicolumn{2}{|l|}{ Tumor size } \\
\hline mean $\pm \mathrm{SD}(\mathrm{cm})$ & $7.7 \pm 3.6$ \\
\hline \multicolumn{2}{|l|}{ Tumor number } \\
\hline 1 & 68 \\
\hline 2 & 20 \\
\hline 3 & 9 \\
\hline 4 & 3 \\
\hline \multicolumn{2}{|l|}{ Tumor extent } \\
\hline Unilobar & 67 \\
\hline Bilobar & 33 \\
\hline \multicolumn{2}{|l|}{ AFP } \\
\hline$\leq 20(\mathrm{ng} / \mathrm{ml})$ & 52 \\
\hline$>20(\mathrm{ng} / \mathrm{ml})$ & 48 \\
\hline Radiation activity administered (GBq) & $4.24 \pm 1.94$ \\
\hline Target absorbed dose (Gy) & $263.9 \pm 125.8$ \\
\hline Virtual tumor dose (Gy) & $2,005.8 \pm 2,348.9$ \\
\hline \multicolumn{2}{|l|}{ Best target tumor response } \\
\hline $\mathrm{CR}$ & 63 \\
\hline PR & 25 \\
\hline SD & 12 \\
\hline
\end{tabular}

HBV: Hepatitis B virus; HCV: hepatitis C virus; INR: international normalized ratio; AST: aspartate aminotransferase; ALT: alanine aminotransferase; BCLC: Barcelona Clinic Liver Cancer; ECOG: European Cooperative Oncology Group; AFP: alpha-fetoprotein; CR: complete response; PR: partial response; SD: stable disease.

distributed in the treated target tissue, mAD was calculated using the total infused radiation activity and total treated target volume. Assuming that all infused microspheres were distributed only in the tumor, VTAD was calculated using the total infused radiation activity and total tumor volume. The differences in mAD and VTAD values depending on the best tumor responses were evaluated by one-way analysis of variance (ANOVA) and the Student-NewmanKeuls post-hoc test. The performances of mAD and vTAD in predicting complete response were evaluated by receiver operating characteristic (ROC) curve analyses. Two ROC curves from mAD and VTAD were compared using the method by DeLong et al. (14).

Local progressive disease was defined as the regrowth of the primary target tumor, the appearance of a new lesion within the target tumor, or at least a $20 \%$ increase in the sum of diameters of the primary target tumor. If surgical resection or liver transplantation was performed, local progression-free survival was censored on the day of operation. If chemoembolization was performed for the primary target tumor without local progressive disease, local progression-free survival was censored on the day of chemoembolization, owing to the inability to conduct further assessment of local tumor response by radioembolization itself. Progressive disease was defined as local progressive disease, intrahepatic distant recurrence (the appearance of new lesions in the liver), or new extrahepatic metastasis.

Progression-free survival, local progression-free survival, and overall survival were defined as the time measured from the radioembolization. Fisher's exact test and multiple logistic regression analysis with a stepwise forward likelihood ratio were used to reveal the significant factor for achieving a complete response. Progression-free survival, local progression-free survival, and overall survival were obtained using the Kaplan-Meier method, and were compared by the log-rank test. To identify factors affecting progression-free survival and local progression-free survival, baseline characteristics and treatment factors were evaluated using the Cox proportional hazard model. A $p$-value of less than 0.05 was considered statistically significant. All statistical analyses were performed with SPSS version 25.0 software (SPSS, Inc., Chicago, IL, USA) and MedCalc version 18.11.3 software (MedCalc Software bv, Ostend, Belgium).

\section{Results}

Tumor response. Based on best tumor response, 63 patients had complete response (CR), 25 partial response (PR), and 12 stable disease (SD). The $\operatorname{mAD}(p=0.002)$ and vTAD $(p<0.001)$ values were significantly different, depending on the best tumor responses: for both parameters, patients with CR had significantly higher values than the others, while there was no significant difference between PR and SD (Figure 2). In relation to predicting complete response, ROC curve analyses revealed that the area under the curve (AUC) value of the vTAD $[0.875,95 \%$ confidence interval $(C I)=0.794-0.932]$ was significantly higher $(p<0.001)$ than that of the $\operatorname{mAD}(0.697,95 \% \mathrm{CI}=0.597-0.785)$ (Figure 3$)$. The sensitivity and specificity of $\mathrm{mAD}$ (>286 Gy) were $49.2 \%$ and $86.5 \%$, respectively. The sensitivity and specificity of vTAD (>952 Gy) were $81.0 \%$ and $86.5 \%$, respectively. Subgroup analysis of $\mathrm{mAD}$ and $\mathrm{vTAD}$ for prediction of complete response (according to tumor size and number) is summarized in Tables II and III, and Figure 4. By univariate analysis, serum alanine aminotransferase $(\leq 40$ 
A

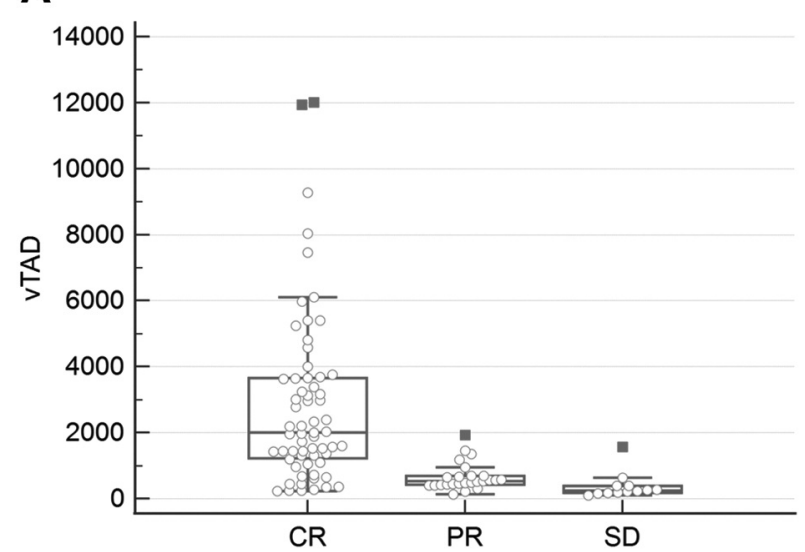

B

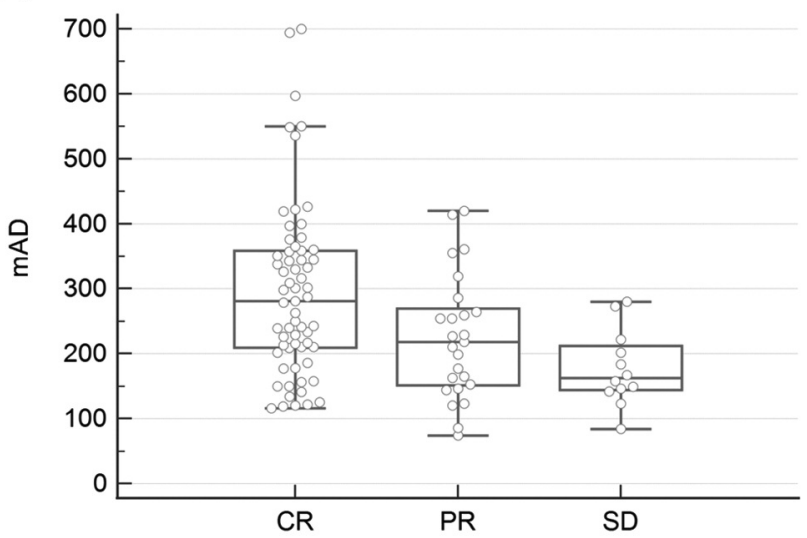

Figure 2. The box-and-whisker plots of (A) mean absorbed dose ( $m A D)$ and $(B)$ virtual tumor absorbed dose (VTAD) values, depending on the best tumor responses following yttrium-90 radioembolization in patients with hepatocellular carcinoma. Note: The central boxes represent the means and interquartile ranges. The vertical lines extend from the minimum to the maximum values, excluding outliers (circles and squares outside the vertical lines, outside and far-out values of Tukey, respectively). CR: Complete response; PR: partial response; SD: stable disease.

IU/1 vs. >40 IU/1), Child-Pugh class (A5 vs. A6/B), primary tumor size $(<7 \mathrm{~cm} v s . \geq 7 \mathrm{~cm}$ ), tumor extent (unilobar $v s$. bilobar disease), mAD (>286 Gy vs. $\leq 286$ Gy), and vTAD (>952 Gy vs. $\leq 952 \mathrm{~Gy}$ ) were revealed as significant factors predicting complete response (Table IV). By multivariate analysis, Child-Pugh class A5, unilobar disease, and vTAD (>952 Gy) were revealed as significant factors predicting complete response (Table V).

Survival. Mean follow-up period was 23.8 months \pm 13.6 (median 21.9 month; range=3.2-53.4 months). Local progression-free survival rates at one, two, and three years were $77.8 \%, 66.4 \%$, and 62.3\%, respectively (Figure 5A). Twenty patients had local progressive disease events: a new

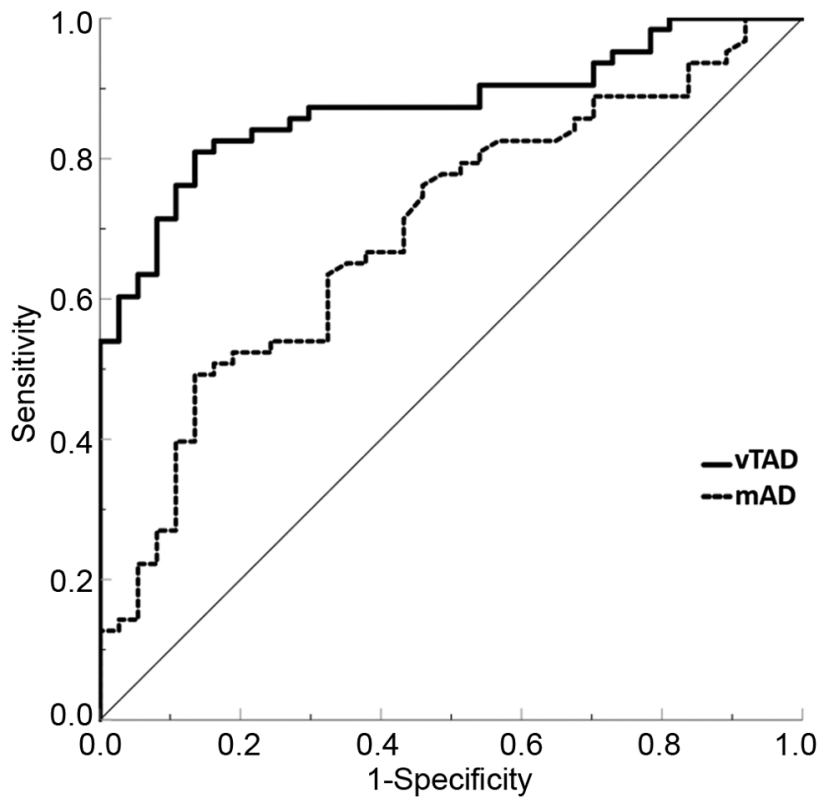

Figure 3. The receiver operating characteristic curves of mean absorbed dose ( $m A D)$ and virtual tumor absorbed dose (vTAD) values in predicting complete response as the best response of yttrium-90 radioembolization in patients with hepatocellular carcinoma.

Table II. Performance of mean absorbed dose (mAD) and virtual tumor absorbed dose (vTAD) in predicting complete response in 100 patients with hepatocellular carcinoma.

\begin{tabular}{lccc}
\hline & AUC & $95 \%$ CI & $p$-Value \\
\hline $\begin{array}{l}\text { All patients }(\mathrm{n}=100) \\
\quad \text { vTAD }\end{array}$ & 0.875 & $0.794-0.932$ & $<0.001$ \\
$\quad$ mAD & 0.697 & $0.597-0.785$ & \\
Subgroup & & & \\
Tumor $<7 \mathrm{~cm}(\mathrm{n}=51)$ & & & 0.022 \\
$\quad$ vTAD & 0.865 & $0.75-0.981$ & \\
$\quad$ mAD & 0.615 & $0.367-0.863$ & 0.791 \\
Tumor $\geq 7$ cm $(\mathrm{n}=49)$ & & & 0.008 \\
$\quad$ vTAD & 0.667 & $0.497-0.837$ & \\
$\quad$ mAD & 0.686 & $0.524-0.847$ & \\
Single tumor $(\mathrm{n}=68)$ & & & \\
$\quad$ vTAD & 0.89 & $0.812-0.968$ & \\
$\quad$ mAD & 0.73 & $0.602-0.858$ & \\
Multiple tumor $(\mathrm{n}=32)$ & & & \\
$\quad$ vTAD & 0.842 & $0.705-0.98$ & \\
$\quad$ mAD & 0.595 & $0.397-0.793$ & \\
\hline
\end{tabular}

lesion within the primary target tumor of complete response $(n=6)$, regrowth of the primary target tumor of partial response $(n=12)$, and a $20 \%$ increase in the sum of diameters of the primary target tumor $(n=2)$. In univariate analysis, Child-Pugh class A5, small tumor $(<7 \mathrm{~cm})$, complete 
Table III. Cut-off value of mean absorbed dose $(m A D)$ and virtual tumor absorbed dose ( $v T A D)$ in predicting complete response in 100 patients with hepatocellular carcinoma.

\begin{tabular}{lcc}
\hline & Sensitivity & Specificity \\
\hline All patients (n=100) & & \\
vTAD $>952$ Gy & $81.0 \%$ & $86.5 \%$ \\
mAD $>286$ Gy & $49.2 \%$ & $86.5 \%$ \\
Subgroup & & \\
Tumor $<7$ cm (n=51) & & \\
vTAD $>1927$ Gy & $73.9 \%$ & $100 \%$ \\
mAD $>280$ Gy & $56.5 \%$ & $80 \%$ \\
Tumor $\geq 7$ cm (n=49) & & \\
vTAD $>692$ Gy & $47.1 \%$ & $93.8 \%$ \\
mAD $>202$ Gy & $82.4 \%$ & $59.4 \%$ \\
Single tumor (n=68) & & \\
vTAD $>692$ Gy & $86.4 \%$ & $87.5 \%$ \\
mAD $>286$ Gy & $54.5 \%$ & $83.3 \%$ \\
Multiple tumor (n=32) & & \\
vTAD $>952$ Gy & $73.7 \%$ & $84.6 \%$ \\
mAD $>259$ Gy & $42.1 \%$ & $92.3 \%$ \\
\hline
\end{tabular}

response, $\mathrm{mAD}>286 \mathrm{~Gy}$, and vTAD >952 Gy were found to be significant factors for longer local progression-free survival (Table VI). In multivariate analysis, complete response was found to be the sole significant factor for longer local progression-free survival ( $p=0.028$ ) (Table VII).

Median progression-free survival was 11.8 months (95\% CI=7.5-16.1 months). Progression-free survival rates at one, two, and three years were $48.8 \%, 35.6 \%$, and $25.4 \%$, respectively (Figure 5B). Fifty-nine patients had progressive disease events: intrahepatic distant recurrence $(n=34)$, local progressive disease $(n=13)$, simultaneous intrahepatic distant recurrence and local progressive disease $(n=2)$, and extrahepatic metastasis $(n=10)$. Five patients had progressive disease (intrahepatic distant recurrence or extrahepatic metastasis) prior to the development of local progressive disease. In univariate analysis, small tumor $(<7 \mathrm{~cm})$, single tumor, complete response, and vTAD >952 Gy were found to be significant factors for longer progression-free survival (Table VIII). In multivariate analysis, single tumor was found to be the sole significant factor for longer progressionfree survival ( $p=0.044)$ (Table IX).

Overall survival rates at one, two, and three years were $88.8 \%, 84.4 \%$, and $76.5 \%$, respectively (Figure 5C).

Complication. Clinical and biochemical toxicities are summarized in Table X. Sixteen events of grade 3 or more clinical toxicity occurred in 12 patients (eight patients of vTAD $\leq 952 \mathrm{~Gy}$, four patients of vTAD >952 Gy). Grade 3 or more biochemical toxicity developed in 14 patients (five patients of vTAD $\leq 952 \mathrm{~Gy}$, nine patients of vTAD >952 Gy).
Table IV. Univariate analysis for predictors of complete response in 100 patients with hepatocellular carcinoma.

\begin{tabular}{|c|c|c|c|c|}
\hline $\begin{array}{l}\text { Patient and tumor } \\
\text { characteristics }\end{array}$ & $\begin{array}{c}\text { Overall } \\
\mathrm{n}=100\end{array}$ & $\begin{array}{c}\mathrm{CR} \\
\mathrm{n}=63\end{array}$ & $\begin{array}{c}\mathrm{PR} \text { or } \mathrm{SD} \\
\mathrm{n}=37\end{array}$ & $p$-Value \\
\hline Gender & & & & 1.0 \\
\hline Men & 84 & 53 & 31 & \\
\hline Women & 16 & 10 & 6 & \\
\hline Age & & & & 0.214 \\
\hline$<65$ & 50 & 35 & 15 & \\
\hline$\geq 65$ & 50 & 28 & 22 & \\
\hline Hepatitis B virus & & & & 0.472 \\
\hline Positive & 77 & 50 & 27 & \\
\hline Negative & 23 & 13 & 10 & \\
\hline Serum albumin & & & & 0.097 \\
\hline$\leq 4.0$ & 53 & 29 & 24 & \\
\hline$>4.0$ & 47 & 34 & 13 & \\
\hline Serum total bilirubin & & & & 0.293 \\
\hline$\leq 0.6$ & 59 & 40 & 19 & \\
\hline$>0.6$ & 41 & 23 & 18 & \\
\hline Prothrombin time & & & & 0.834 \\
\hline$\leq 1.0 \mathrm{INR}$ & 39 & 24 & 15 & \\
\hline$>1.0 \mathrm{INR}$ & 61 & 39 & 22 & \\
\hline Serum AST level & & & & 0.048 \\
\hline$\leq 40(\mathrm{IU} / \mathrm{l})$ & 67 & 47 & 20 & \\
\hline$>40(\mathrm{IU} / \mathrm{l})$ & 33 & 16 & 17 & \\
\hline Serum ALT level & & & & 0.007 \\
\hline$\leq 40(\mathrm{IU} / \mathrm{l})$ & 69 & 50 & 19 & \\
\hline$>40(\mathrm{IU} / \mathrm{l})$ & 31 & 13 & 18 & \\
\hline Serum $\alpha$-fetoprotein & & & & 1.0 \\
\hline$\leq 20(\mathrm{ng} / \mathrm{ml})$ & 52 & 33 & 19 & \\
\hline$>20(\mathrm{ng} / \mathrm{ml})$ & 48 & 30 & 18 & \\
\hline Platelet & & & & 0.149 \\
\hline$\geq 170 \mathrm{~K}$ & 55 & 31 & 24 & \\
\hline$<170 \mathrm{~K}$ & 45 & 32 & 13 & \\
\hline Child-Pugh Class & & & & 0.000 \\
\hline A5 & 84 & 60 & 24 & \\
\hline A6/B & 16 & 3 & 13 & \\
\hline Tumor number & & & & 0.66 \\
\hline Single & 68 & 44 & 24 & \\
\hline Multiple & 32 & 19 & 13 & \\
\hline Primary tumor size & & & & 0.000 \\
\hline$<7 \mathrm{~cm}$ & 51 & 46 & 5 & \\
\hline$\geq 7 \mathrm{~cm}$ & 49 & 17 & 32 & \\
\hline Tumor extent & & & & 0.000 \\
\hline Unilobar & 67 & 53 & 14 & \\
\hline Bilobar & 33 & 10 & 23 & \\
\hline Target absorbed dose & & & & 0.000 \\
\hline$\leq 286 \mathrm{~Gy}$ & 64 & 32 & 32 & \\
\hline$>286 \mathrm{~Gy}$ & 36 & 31 & 5 & \\
\hline Virtual tumor dose & & & & 0.000 \\
\hline$\leq 952 \mathrm{~Gy}$ & 45 & 13 & 32 & \\
\hline$>952 \mathrm{~Gy}$ & 55 & 50 & 5 & \\
\hline
\end{tabular}

AST: Aspartate aminotransferase; ALT: alanine aminotransferase; CR: complete response; PR: partial response; SD: stable disease.

\section{Discussion}

The vTAD can be simply calculated using the total radiation activity administered and the total tumor volume by the MIRD method without involvement of MAA SPECT/CT. 
A

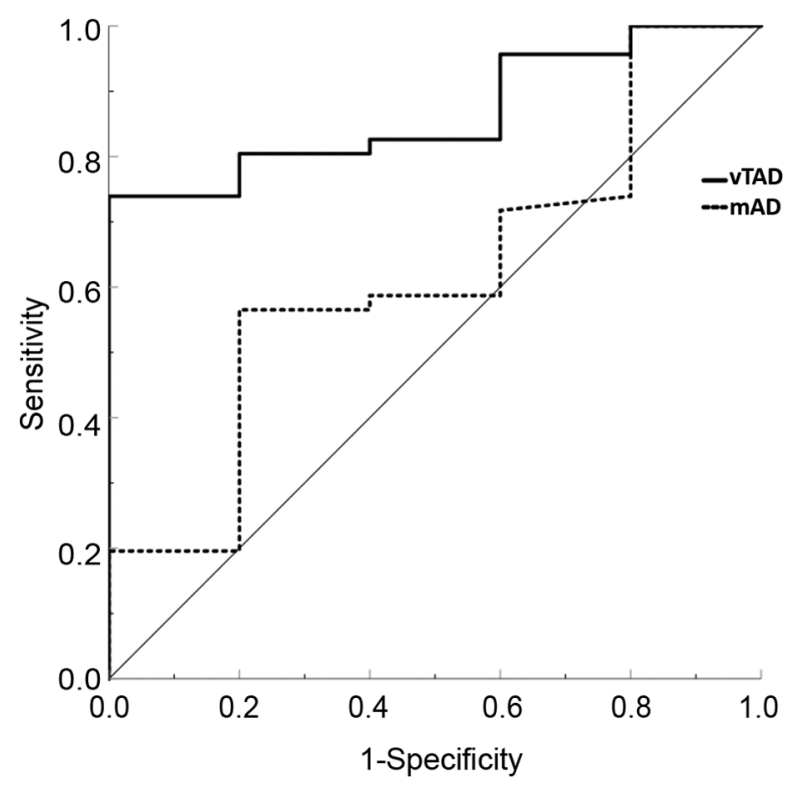

C

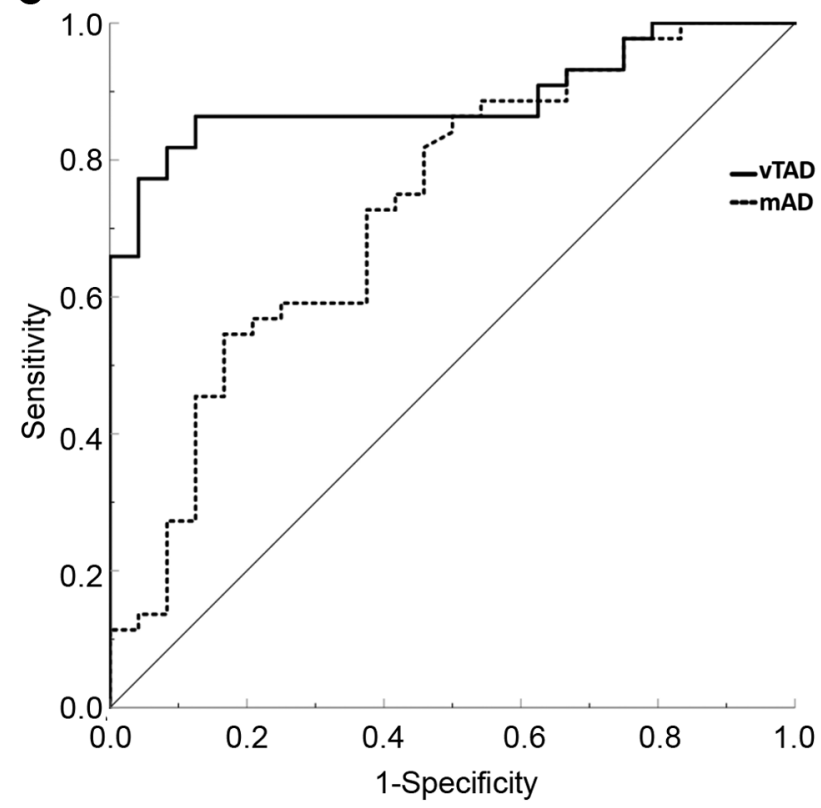

B

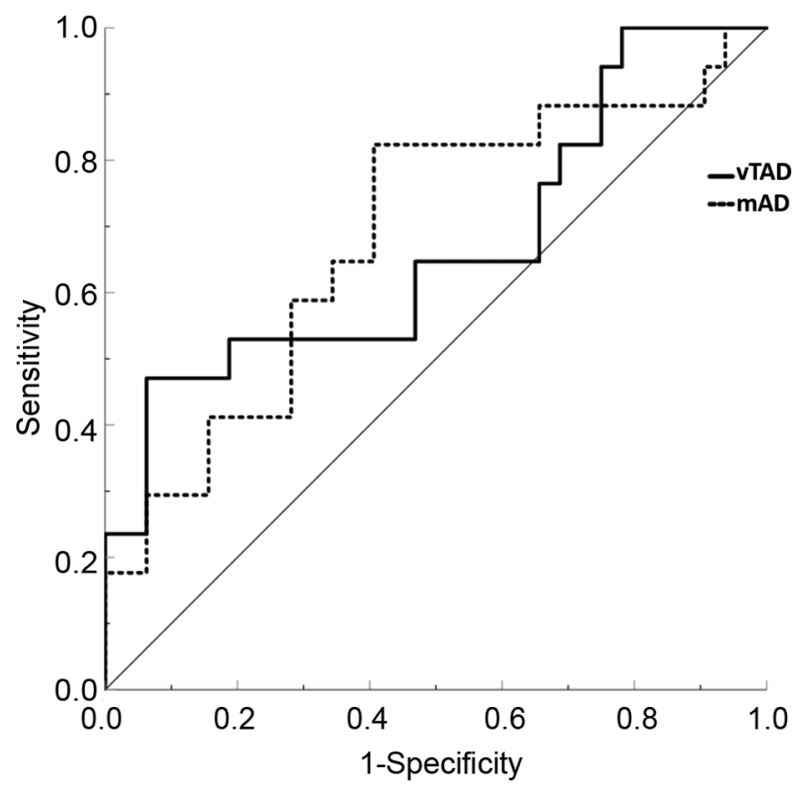

D

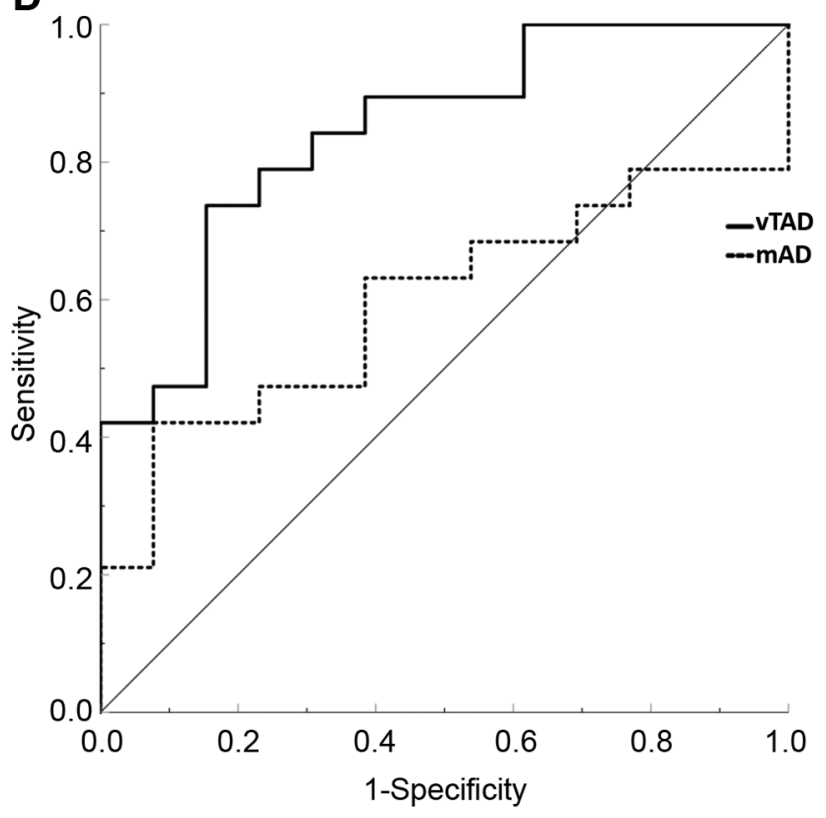

Figure 4. The receiver operating characteristic curves of mean absorbed dose ( $m A D)$ and virtual tumor absorbed dose (vTAD) values in predicting complete response as the best response of yttrium-90 radioembolization in patients with hepatocellular carcinoma. (A) subgroup of tumor $<7 \mathrm{~cm}$, (B) subgroup of tumor $\geq 7 \mathrm{~cm}$, (C) subgroup of single nodular tumor, (D) subgroup of multinodular tumors.

Table V. Multivariate analysis for predictors of complete response in 100 patients with hepatocellular carcinoma.

\begin{tabular}{lccc}
\hline Patient and tumor characteristics & Hazard ratio & $95 \%$ CI & $p$-Value \\
\hline Child-Pugh Class (A5 vs. A6/B) & 5.721 & $1.175-27.862$ & 0.031 \\
Tumor extent (unilobar $v$ s. bilobar) & 6.4 & $1.93-21.221$ & 0.002 \\
Virtual tumor dose ( $>952$ Gy $v$ s. $\leq 952$ Gy) & 13.377 & $3.899-45.896$ & 0.000 \\
\hline
\end{tabular}


Table VI. Univariate analysis for local progression-free survival in 100 patients with hepatocellular carcinoma.

\begin{tabular}{|c|c|c|c|c|c|}
\hline \multirow[t]{2}{*}{$\begin{array}{l}\text { Patient and tumor } \\
\text { characteristics }\end{array}$} & \multirow[t]{2}{*}{$\begin{array}{c}\text { Overall } \\
\mathrm{n}=100\end{array}$} & \multicolumn{3}{|c|}{$\begin{array}{c}\text { Local progression-free } \\
\text { survival }(\%)\end{array}$} & \multirow[t]{2}{*}{$p$-Value } \\
\hline & & 6 months & 1 year & 2 year & \\
\hline \multicolumn{5}{|l|}{ Gender } & 0.431 \\
\hline Men & 84 & 96.9 & 80.2 & 67.2 & \\
\hline Women & 16 & 78.0 & 66.9 & 66.9 & \\
\hline \multicolumn{5}{|l|}{ Age } & 0.220 \\
\hline$<65$ & 50 & 97.5 & 82.0 & 71.3 & \\
\hline$\geq 65$ & 50 & 90.3 & 74.8 & 62.5 & \\
\hline \multicolumn{5}{|l|}{ Hepatitis B virus } & 0.907 \\
\hline Positive & 77 & 92.7 & 78.0 & 65.9 & \\
\hline Negative & 23 & 95.2 & 77.2 & 67.6 & \\
\hline \multicolumn{5}{|l|}{ Serum Albumin } & 0.252 \\
\hline$\leq 4.0$ & 53 & 89.2 & 74.6 & 63.3 & \\
\hline$>4.0$ & 47 & 97.6 & 81.1 & 69.7 & \\
\hline \multicolumn{5}{|l|}{ Serum total bilirubin } & 0.466 \\
\hline$\leq 0.6$ & 59 & 93.6 & 80.2 & 61.8 & \\
\hline$>0.6$ & 41 & 92.9 & 73.5 & 73.5 & \\
\hline \multicolumn{5}{|l|}{ Prothrombin time } & 0.802 \\
\hline$\leq 1.0 \mathrm{INR}$ & 39 & 93.0 & 75.9 & 63.2 & \\
\hline$>1.0 \mathrm{INR}$ & 61 & 93.7 & 79.3 & 69.4 & \\
\hline \multicolumn{5}{|l|}{ Serum AST level } & 0.925 \\
\hline$\leq 40(\mathrm{IU} / \mathrm{l})$ & 67 & 92.1 & 76.6 & 64.7 & \\
\hline$>40(\mathrm{IU} / \mathrm{l})$ & 33 & 96.2 & 80.3 & 71.4 & \\
\hline \multicolumn{5}{|l|}{ Serum ALT level } & 0.649 \\
\hline$\leq 40(\mathrm{IU} / \mathrm{l})$ & 69 & 92.1 & 80.5 & 66.3 & \\
\hline$>40(\mathrm{IU} / \mathrm{l})$ & 31 & 96.4 & 68.8 & 68.8 & \\
\hline \multicolumn{5}{|l|}{ Serum $\alpha$-fetoprotein } & 0.930 \\
\hline$\leq 20(\mathrm{ng} / \mathrm{ml})$ & 52 & 94.4 & 75.5 & 71.0 & \\
\hline$>20(\mathrm{ng} / \mathrm{ml})$ & 48 & 92.7 & 81.3 & 60.4 & \\
\hline \multicolumn{5}{|l|}{ Platelet } & 0.269 \\
\hline$\geq 170 \mathrm{~K}$ & 55 & 98.0 & 73.3 & 55.9 & \\
\hline$<170 \mathrm{~K}$ & 45 & 87.5 & 83.5 & 78.3 & \\
\hline \multicolumn{5}{|l|}{ Child-Pugh Class } & 0.025 \\
\hline A5 & 84 & 95.3 & 81.2 & 71.8 & \\
\hline A6/B & 16 & 82.5 & 55.0 & 27.5 & \\
\hline \multicolumn{5}{|l|}{ Tumor number } & 0.876 \\
\hline Single & 68 & 89.6 & 76.9 & 68.2 & \\
\hline Multiple & 32 & 100 & 78.8 & 62.7 & \\
\hline \multicolumn{5}{|l|}{ Primary tumor size } & 0.002 \\
\hline$<7 \mathrm{~cm}$ & 51 & 97.3 & 89.9 & 84.2 & \\
\hline$\geq 7 \mathrm{~cm}$ & 49 & 89.6 & 65.2 & 45.7 & \\
\hline \multicolumn{5}{|l|}{ Tumor extent } & 0.782 \\
\hline Unilobar & 67 & 92.3 & 79.4 & 69.9 & \\
\hline Bilobar & 33 & 95.8 & 75.9 & 61.8 & \\
\hline \multicolumn{5}{|l|}{ Tumor response } & 0.001 \\
\hline Complete response & se 63 & 100 & 91.7 & 79.8 & \\
\hline $\begin{array}{l}\text { Partial response/ } \\
\text { Stable disease }\end{array}$ & 37 & 81.3 & 50.1 & 40.1 & \\
\hline \multicolumn{5}{|l|}{ Target absorbed dose } & 0.002 \\
\hline$\leq 286 \mathrm{~Gy}$ & 64 & 89.7 & 67.7 & 51.9 & \\
\hline$>286$ Gy & 36 & 100 & 95.5 & 95.5 & \\
\hline Virtual tumor dose & & & & & 0.001 \\
\hline$\leq 952 \mathrm{~Gy}$ & 45 & 86.2 & 61.3 & 38.3 & \\
\hline$>952$ Gy & 55 & 100 & 93.3 & 93.3 & \\
\hline
\end{tabular}

AST: Aspartate aminotransferase; ALT: alanine aminotransferase; CR: complete response; PR: partial response; SD: stable disease.
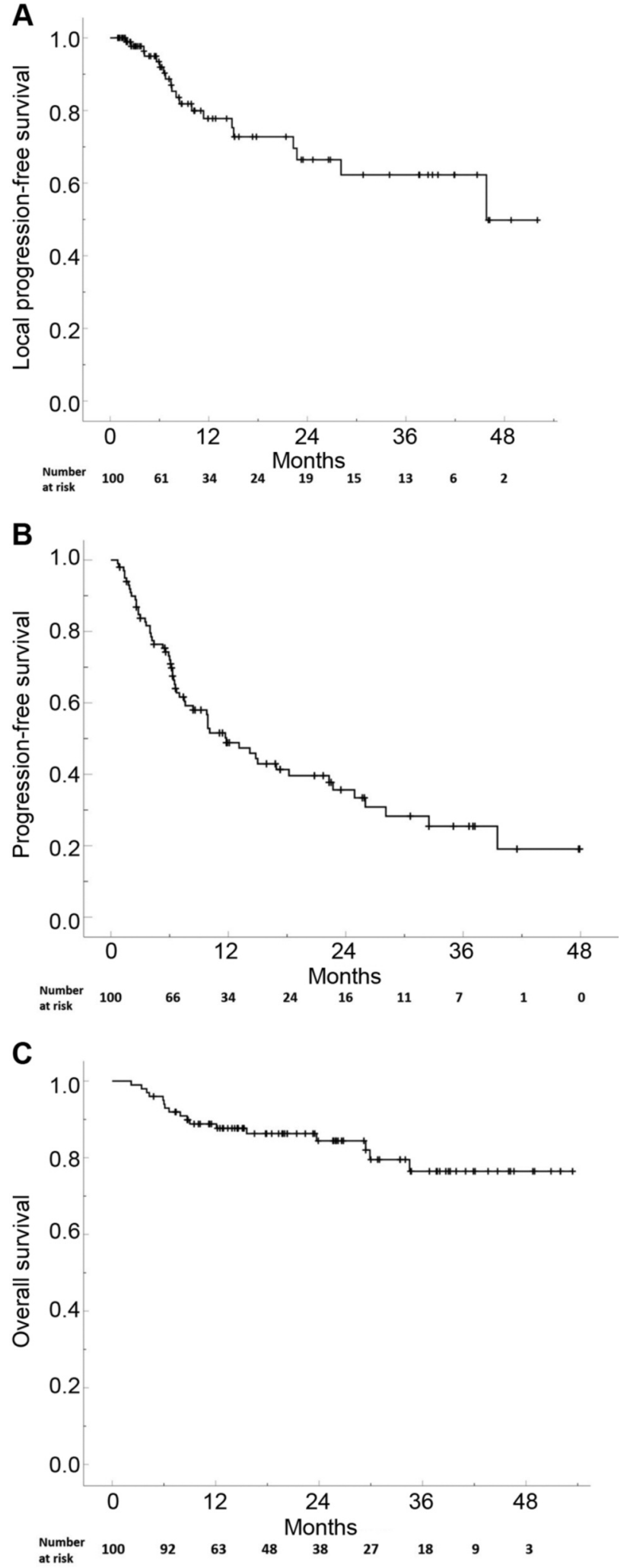

Figure 5. Graphs illustrate local progression-free survival (A), progressionfree survival $(B)$, and overall survival $(C)$ in patients with nodular hepatocellular carcinoma treated with yttrium-90 radioembolization. 
Table VII. Multivariate analysis for local progression-free survival in 100 patients with hepatocellular carcinoma.

\begin{tabular}{lccc}
\hline Patient and tumor characteristics & Hazard ratio & $95 \%$ CI & $p$-Value \\
\hline Child-Pugh class (A5 $v s$. A6/B) & 0.570 & $0.188-1.725$ & 0.319 \\
Tumor size $(<7 \mathrm{~cm} v s . \geq 7 \mathrm{~cm})$ & 0.893 & $0.212-3.755$ & 0.877 \\
Tumor response $(\mathrm{CR} v s$. PR/SD) & 0.264 & $0.081-0.867$ & 0.028 \\
Target absorbed dose $(>286$ Gy $v s . \leq 286$ Gy) & 0.219 & $0.025-1.945$ & 0.173 \\
Virtual tumor dose $(>952$ Gy $v s . \leq 952$ Gy) & 0.435 & $0.059-3.191$ & 0.413 \\
\hline
\end{tabular}

Because the basic assumption is that all radioactive microspheres are deposited in the tumor, the authors admit that the vTAD differs from the TAD. However, the vTAD can have a value similar to the TAD in hypervascular tumors, particularly in large HCCs. The present study demonstrated vTAD (>952 Gy) as a predictor of complete tumor response in nodular HCCs, and high vTAD has a better performance than high $\mathrm{mAD}$ in predicting complete tumor response. This finding means that the radiation activity prescribed should be proportional to the tumor volume rather than the target liver volume.

The standard dosimetry of MIRD estimates the mAD of the target tissue and cannot reflect the preferential delivery of radioactive microspheres in the hypervascular tumor. Thus, personalized dosimetry using MAA SPECT/CT has been tried in several studies, with promising results (7-9). However, personalized dosimetry using MAA SPECT/CT requires significant time and laborious work in the field of nuclear medicine. In addition, in terms of physical characteristics such as density and morphology, MAA differs from glass or resin microspheres and cannot follow the exact distribution of radioactive microspheres. Retrospective studies reported a weak correlation between the predicted and actual TAD (15-17) owing to the physical differences between MAA and radioactive microspheres, as well as different catheter tip position and injection speed, etc.

Post-treatment Y90 positron emission tomography/ computed tomography (PET/CT) can provide highly accurate TAD (18), and a recent prospective trial demonstrated that responders had a higher median TAD than non-responders (225 Gy vs. 83 Gy) (19). However, post-treatment dosimetry using Y90 PET/CT cannot optimize the radioembolization procedure itself, but it can guide the subsequent adjuvant therapy if indicated. Thus, the concept of VTAD can serve as a simple guide for a tailored radioembolization procedure, although the optimal cut-off value of vTAD has not yet been determined.

Compared with the TAD calculated from the MAA SPECT/CT, the VTAD can be simply and accurately obtained from CT or magnetic resonance imaging (MRI). Because all infused Y90 microspheres are assumed to be delivered only in the tumor, the value of vTAD is always overestimated when compared with the TAD computed from MAA SPECT/CT or Y90 PET/CT. The TAD would be somewhere between the mAD and the vTAD. When the large hypervascular tumor is treated and the volume of treated normal liver is small, the vTAD is close to the TAD. If the target tumor is small and a large normal liver is included in the target tissue, the vTAD would be much higher than the TAD.

The vTAD of 952 Gy threshold used in this study is not to be considered as the absolute cut-off value for complete tumor response. In the prospective study, the TAD of 205 Gy using MAA SPECT/CT was adopted as a threshold (9). Thus, the vTAD of 952 Gy is much higher than that used in the current clinical practice. The optimal threshold of vTAD may be lower than 952 Gy in a patient with a large tumor and may be higher than 952 Gy in a patient with a small tumor. In subgroup analysis, the threshold of vTAD was $1927 \mathrm{~Gy}$ in tumors $<7 \mathrm{~cm}$, and $692 \mathrm{~Gy}$ in tumors $\geq 7 \mathrm{~cm}$. In addition, the 952 Gy threshold was designed for complete tumor response. If a bridge to the liver transplantation is scheduled or combined systemic therapy is planned owing to extrahepatic metastasis, the threshold of vTAD could be lowered because the goal of radioembolization may be partial tumor response without serious complications. Further studies with a large study population are needed to determine the optimal threshold of vTAD in various situations.

A prospective multi-center study using Y90 glass microspheres demonstrated that the personalized dosimetry group (TAD > $205 \mathrm{~Gy}$ ) had a better objective response rate and overall survival than the standard dosimetry group (120 \pm 20 Gy of TAD) (9). The personalized dosimetry group had a $21 \%$ complete response rate and a $71 \%$ objective response rate, whereas the standard dosimetry group had an $11 \%$ complete response rate and a $36 \%$ objective response rate. Even though the present study was not involved with personalized dosimetry with MAA SPECT/CT, the tumor response $(63 \%$ complete response rate and $88 \%$ objective response rate) was excellent compared with the above prospective study because most patients were treated with boosted radioembolization (263.9 Gy of mAD). 
Table VIII. Univariate analysis for progression-free survival in 100 patients with hepatocellular carcinoma.

\begin{tabular}{|c|c|c|c|}
\hline $\begin{array}{l}\text { Patient and tumor } \\
\text { characteristics }\end{array}$ & $\begin{array}{c}\text { Overall } \\
\mathrm{n}=100\end{array}$ & $\begin{array}{c}\text { Median PFS } \\
(95 \% \mathrm{CI}) \text { (months) }\end{array}$ & $p$-Value \\
\hline Gender & & & 0.104 \\
\hline Men & 84 & $6.2(0.5 \sim 11.9)$ & \\
\hline Women & 16 & $14.2(7.2 \sim 21.2)$ & \\
\hline Age & & & 0.496 \\
\hline$<65$ & 50 & $11.7(6.6 \sim 16.8)$ & \\
\hline$\geq 65$ & 50 & $13.1(4.8 \sim 21.4)$ & \\
\hline Hepatitis B virus & & & 0.963 \\
\hline Positive & 77 & $11.7(7.4 \sim 16.0)$ & \\
\hline Negative & 23 & $14.2(1.8 \sim 26.6)$ & \\
\hline Serum albumin & & & 0.076 \\
\hline$\leq 4.0$ & 53 & $9.9(7.6 \sim 12.2)$ & \\
\hline$>4.0$ & 47 & $18.2(4.4 \sim 32.0)$ & \\
\hline Serum total bilirubin & & & 0.293 \\
\hline$\leq 0.6$ & 59 & $14.8(7.6 \sim 21.9)$ & \\
\hline$>0.6$ & 41 & $7.0(2.1 \sim 11.8)$ & \\
\hline Prothrombin time & & & 0.941 \\
\hline$\leq 1.0 \mathrm{INR}$ & 39 & $10.1(6.9 \sim 13.3)$ & \\
\hline$>1.0 \mathrm{INR}$ & 61 & $14.2(3.9 \sim 24.4)$ & \\
\hline Serum AST level & & & 0.393 \\
\hline$\leq 40(\mathrm{IU} / \mathrm{l})$ & 67 & $13.1(6.4 \sim 19.7)$ & \\
\hline$>40(\mathrm{IU} / \mathrm{l})$ & 33 & $7.6(3.6 \sim 11.6)$ & \\
\hline Serum ALT level & & & 0.492 \\
\hline$\leq 40(\mathrm{IU} / \mathrm{l})$ & 69 & $11.7(7.4 \sim 15.9)$ & \\
\hline$>40(\mathrm{IU} / \mathrm{l})$ & 31 & $24.9(0.0 \sim 58.3)$ & \\
\hline Serum $\alpha$-fetoprotein & & & 0.082 \\
\hline$\leq 20(\mathrm{ng} / \mathrm{ml})$ & 52 & $15.0(6.6 \sim 23.4)$ & \\
\hline$>20(\mathrm{ng} / \mathrm{ml})$ & 48 & $9.9(6.1 \sim 13.7)$ & \\
\hline Platelet & & & 0.194 \\
\hline$\geq 170 \mathrm{~K}$ & 55 & $9.9(5.3 \sim 14.5)$ & \\
\hline$<170 \mathrm{~K}$ & 45 & $15.0(1.3 \sim 28.7)$ & \\
\hline Child-Pugh Class & & & 0.083 \\
\hline A5 & 84 & $14.2(8.6 \sim 19.8)$ & \\
\hline A6/B & 16 & $6.2(0.3 \sim 12.1)$ & \\
\hline Tumor number & & & 0.016 \\
\hline Single & 68 & $22.7(8.1 \sim 37.3)$ & \\
\hline Multiple & 32 & $7.0(5.3 \sim 8.6)$ & \\
\hline Primary tumor size & & & 0.01 \\
\hline$<7 \mathrm{~cm}$ & 51 & $22.3(8.0 \sim 36.6)$ & \\
\hline$\geq 7 \mathrm{~cm}$ & 49 & $6.7(2.7 \sim 10.7)$ & \\
\hline Tumor extent & & & 0.293 \\
\hline Unilobar & 67 & $14.2(6.0 \sim 22.3)$ & \\
\hline Bilobar & 33 & $9.8(4.5 \sim 15.1)$ & \\
\hline Tumor response & & & 0.001 \\
\hline Complete response & 63 & $22.3(11.6 \sim 33.0)$ & \\
\hline $\begin{array}{l}\text { Partial response/ } \\
\text { Stable disease }\end{array}$ & 37 & $6.4(5.8 \sim 7.0)$ & \\
\hline Target absorbed dose & & & 0.127 \\
\hline$\leq 286$ Gy & 64 & $9.9(5.4 \sim 14.4)$ & \\
\hline >286 Gy & 36 & $18.2(0.0 \sim 39.4)$ & \\
\hline Virtual tumor dose & & & 0.002 \\
\hline$\leq 952 \mathrm{~Gy}$ & 45 & $6.5(3.4 \sim 9.6)$ & \\
\hline$>952 \mathrm{~Gy}$ & 55 & $26.0(5.5 \sim 46.5)$ & \\
\hline
\end{tabular}

AST: Aspartate aminotransferase; ALT: alanine aminotransferase; CR: complete response; PR: partial response; SD: stable disease.
This study has several limitations. First, the TAD was not measured with Y90 PET/CT or MAA SPECT/CT. Because the vTAD was not directly compared with the TAD measured with Y90 PET/CT, it is unknown how much the vTAD overestimated the TAD. Further study is needed to reveal the relationship between the vTAD and TAD measured by Y90 PET/CT. Second, most of the study population was treated with boosted radioembolization (200 360 Gy of mAD) if possible. Thus, the ROC curve analysis suggested the vTAD of $952 \mathrm{~Gy}$ and the mAD of $286 \mathrm{~Gy}$ as a threshold for prediction of complete response. If more patients had been treated with standard dosimetry (80 150 Gy of mAD), the threshold would have been lower. Third, the high vTAD > 952 Gy was a significant factor for complete response, but was not a significant factor for longer progression-free survival. In addition, because of the relatively short followup period, overall survival was not analyzed. Fourth, the exact tumor volume cannot be measured on CT or MRI in patients with infiltrative HCC. Thus, the vTAD cannot be applied in such patients. Fifth, all patients were treated with glass microspheres in this study. If resin microspheres are used, the threshold of vTAD may be different.

In conclusion, when the vTAD is calculated assuming that all radioactive microspheres are deposited in the $\mathrm{HCC}$, high vTAD (>952 Gy) plays a significant role in complete response in patients with nodular HCC. The vTAD has better ability than $\mathrm{mAD}$ in terms of prediction of complete response in patient with nodular HCC, which means that the radiation activity prescribed should be proportional to the tumor volume rather than the target liver volume.

\section{Conflicts of Interest}

The Authors have no conflicts of interest to disclose in relation to this study.

\section{Authors' Contributions}

Guarantor of integrity of the entire study: Hyo-Cheol Kim. Study concepts and design: Hyo-Cheol Kim. Literature research: Hyo-Cheol Kim, Myungsu Lee, Jin Chul Paeng. Clinical studies: Hyo-Cheol Kim, Myungsu Lee, Yoon Jun Kim, Jin Chul Paeng, Jin Wook Chung. Data analysis: Hyo-Cheol Kim, Myungsu Lee, Jin Chul Paeng. Stastitical analysis: Hyo-Cheol Kim, Myungsu Lee, Yoon Jun Kim. Manuscript preparation: Hyo-Cheol Kim. Manuscript editing: Myungsu Lee, Yoon Jun Kim, Jin Chul Paeng, Jin Wook Chung.

\section{References}

1 Salem R, Gordon AC, Mouli S, Hickey R, Kallini J, Gabr A, Mulcahy MF, Baker T, Abecassis M, Miller FH, Yaghmai V, Sato K, Desai K, Thornburg B, Benson AB, Rademaker A, Ganger D, Kulik L and Lewandowski RJ: Y90 radioembolization significantly prolongs time to progression compared with chemoembolization in patients with hepatocellular carcinoma. 
Table IX. Multivariate analysis for progression-free survival in 100 patients with hepatocellular carcinoma.

\begin{tabular}{lccc}
\hline Patient and tumor characteristics & Hazard ratio & $95 \% \mathrm{CI}$ & $p$-Value \\
\hline Tumor size $(<7 \mathrm{~cm} v s . \geq 7 \mathrm{~cm})$ & 0.852 & $0.385-1.884$ & 0.692 \\
Tumor number (single $v s$. multiple) & 0.584 & $0.345-0.987$ & 0.044 \\
Tumor response (CR $v$. PR/SD) & 0.583 & $0.278-1.223$ & 0.153 \\
Virtual tumor dose $(>952$ Gy $v s . \leq 952 \mathrm{~Gy})$ & 0.752 & $0.301-1.878$ & 0.541 \\
\hline
\end{tabular}

CR: Complete response; PR: partial response; SD: stable disease.

Table X. Toxicity from radioembolization in 100 patients with hepatocellular carcinoma.

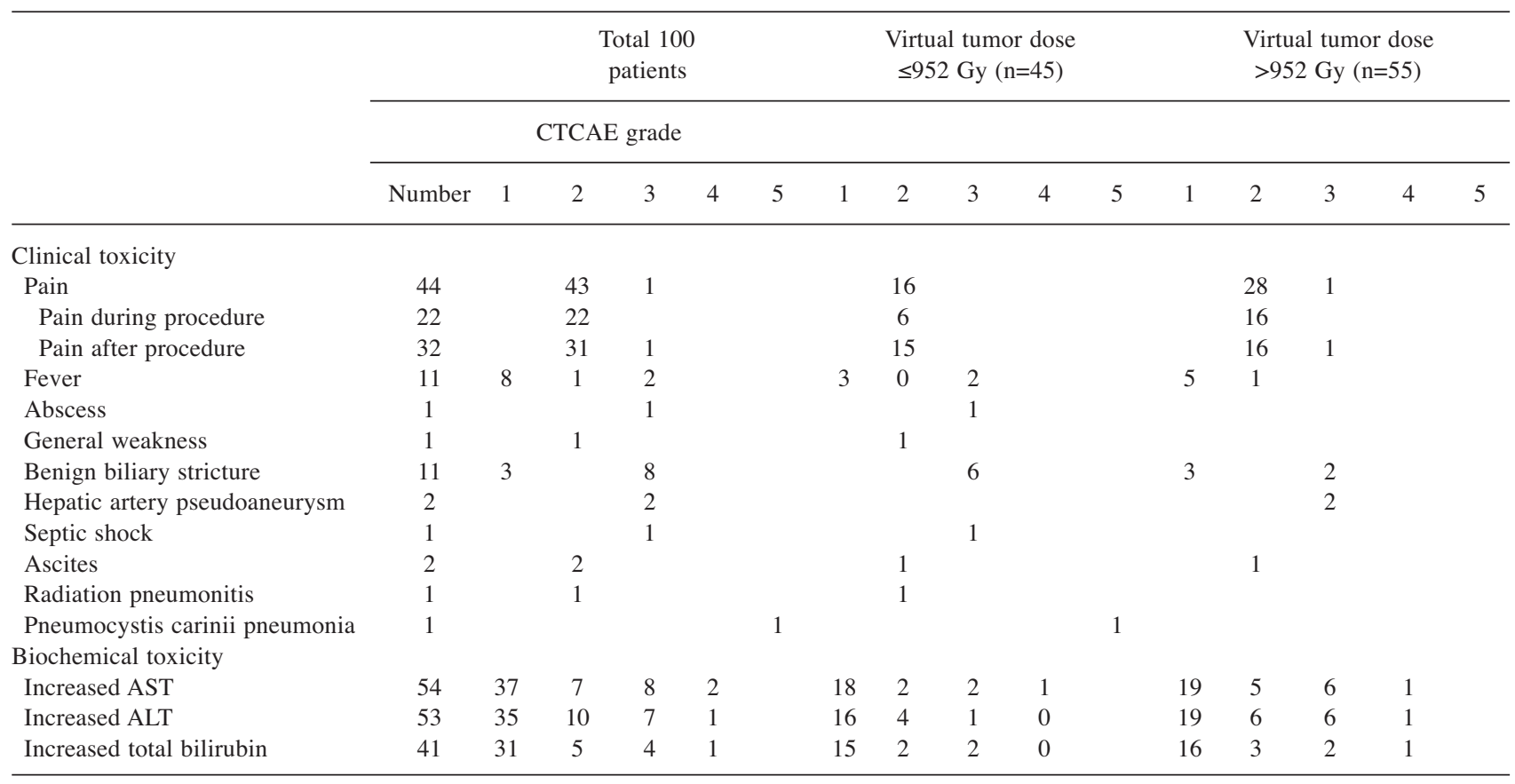

ALT: Alanine aminotransferase; AST: aspartate aminotransferase; CTCAE: Common terminology criteria for adverse events.

Gastroenterology 151(6): 1155-1163.e2, 2016. PMID: 27575820. DOI: $10.1053 /$ j.gastro.2016.08.029

2 Salem R, Gilbertsen M, Butt Z, Memon K, Vouche M, Hickey R, Baker T, Abecassis MM, Atassi R, Riaz A, Cella D, Burns JL, Ganger D, Benson AB 3rd, Mulcahy MF, Kulik L and Lewandowski R: Increased quality of life among hepatocellular carcinoma patients treated with radioembolization, compared with chemoembolization. Clin Gastroenterol Hepatol 11(10): 1358-1365.e1, 2013. PMID: 23644386. DOI: 10.1016/j.cgh. 2013.04.028

3 Omata M, Cheng AL, Kokudo N, Kudo M, Lee JM, Jia J, Tateishi R, Han KH, Chawla YK, Shiina S, Jafri W, Payawal DA, Ohki T, Ogasawara S, Chen PJ, Lesmana CRA, Lesmana LA, Gani RA, Obi S, Dokmeci AK and Sarin SK: Asia-Pacific clinical practice guidelines on the management of hepatocellular carcinoma: A 2017 update. Hepatol Int 11(4): 317-370, 2017. PMID: 28620797. DOI: 10.1007/s12072-017-9799-9
4 Garin E, Rolland Y, Edeline J, Icard N, Lenoir L, Laffont S, Mesbah H, Breton M, Sulpice L, Boudjema K, Rohou T, Raoul JL, Clement B and Boucher E: Personalized dosimetry with intensification using 90 Y-loaded glass microsphere radioembolization induces prolonged overall survival in hepatocellular carcinoma patients with portal vein thrombosis. J Nucl Med 56(3): 339-346, 2015. PMID: 25678490. DOI: 10.2967/jnumed.114.145177

5 Vouche M, Habib A, Ward TJ, Kim E, Kulik L, Ganger D, Mulcahy M, Baker T, Abecassis M, Sato KT, Caicedo JC, Fryer J, Hickey R, Hohlastos E, Lewandowski RJ and Salem R: Unresectable solitary hepatocellular carcinoma not amenable to radiofrequency ablation: Multicenter radiology-pathology correlation and survival of radiation segmentectomy. Hepatology 60(1): 192-201, 2014. PMID: 24691943. DOI: 10.1002/hep.27057

6 Salem R, Padia SA, Lam M, Bell J, Chiesa C, Fowers K, Hamilton B, Herman J, Kappadath SC, Leung T, Portelance L, 
Sze D and Garin E: Clinical and dosimetric considerations for Y90: Recommendations from an international multidisciplinary working group. Eur J Nucl Med Mol Imaging 46(8): 1695-1704, 2019. PMID: 31098749 . DOI: 10.1007/s00259-019-04340-5

7 Tafti BA and Padia SA: Dosimetry of Y-90 microspheres utilizing Tc-99m SPECT and Y-90 PET. Semin Nucl Med 49(3): 211-217, 2019. PMID: 30954187. DOI: 10.1053/j.semnuclmed. 2019.01 .005

8 Garin E, Rolland Y and Edeline J: ${ }^{90}$ Y-loaded microsphere SIRT of HCC patients with portal vein thrombosis: High clinical impact of 99mTc-MAA SPECT/CT-based dosimetry. Semin Nucl Med 49(3): 218-226, 2019. PMID: 30954188. DOI: 10.1053/j.semnuclmed.2019.01.006

9 Garin E, Tselikas L, Guiu B, Chalaye J, Edeline J, de Baere T, Assenat E, Tacher V, Robert C, Terroir-Cassou-Mounat M, Mariano-Goulart D, Amaddeo G, Palard X, Hollebecque A, Kafrouni M, Regnault H, Boudjema K, Grimaldi S, Fourcade M, Kobeiter H, Vibert E, Le Sourd S, Piron L, Sommacale D Laffont S, Campillo-Gimenez B, Rolland Y and DOSISPHERE01 Study Group: Personalised versus standard dosimetry approach of selective internal radiation therapy in patients with locally advanced hepatocellular carcinoma (DOSISPHERE-01): A randomised, multicentre, open-label phase 2 trial. Lancet Gastroenterol Hepatol 6(1): 17-29, 2021. PMID: 33166497 DOI: $10.1016 / \mathrm{S} 2468-1253(20) 30290-9$

10 Kim HC, Kim YJ, Lee JH, Suh KS and Chung JW: Feasibility of boosted radioembolization for hepatocellular carcinoma larger than $5 \mathrm{~cm}$. J Vasc Interv Radiol 30(1): 1-8, 2019. PMID: 30293734. DOI: 10.1016/j.jvir.2018.07.002

11 Choi JW, Yoo MY, Kim HC, Paeng JC, Kim YJ and Chung JW: Prophylactic temporary occlusion of the cystic artery using a fibered detachable coil during ${ }^{90} \mathrm{Y}$ radioembolization. Cardiovasc Intervent Radiol 40(10): 1624-1630, 2017. PMID: 28500460. DOI: $10.1007 / \mathrm{s} 00270-017-1688-\mathrm{Z}$

$12 \mathrm{Kim}$ HC, Kim YJ, Paeng JC and Chung JW: Yttrium-90 radioembolization of the right inferior phrenic artery in 20 patients with hepatocellular carcinoma. J Vasc Interv Radiol 29(4): 556-563, 2018. PMID: 29373246. DOI: 10.1016/ j.jvir.2017.10.010

13 Lencioni R and Llovet JM: Modified RECIST (mRECIST) assessment for hepatocellular carcinoma. Semin Liver Dis 30(1): 52-60, 2010. PMID: 20175033. DOI: 10.1055/s-0030-1247132
14 DeLong ER, DeLong DM and Clarke-Pearson DL: Comparing the areas under two or more correlated receiver operating characteristic curves: A nonparametric approach. Biometrics 44(3): 837-845, 1988. PMID: 3203132.

15 Haste P, Tann M, Persohn S, LaRoche T, Aaron V, Mauxion T, Chauhan N, Dreher MR and Johnson MS: Correlation of technetium-99m macroaggregated albumin and yttrium-90 glass microsphere biodistribution in hepatocellular carcinoma: A retrospective review of pretreatment single photon emission CT and posttreatment positron emission tomography/CT. J Vasc Interv Radiol 28(5): 722-730.e1, 2017. PMID: 28238581. DOI: 10.1016/j.jvir.2016.12.1221

16 Lea WB, Tapp KN, Tann M, Hutchins GD, Fletcher JW and Johnson MS: Microsphere localization and dose quantification using positron emission tomography/CT following hepatic intraarterial radioembolization with yttrium-90 in patients with advanced hepatocellular carcinoma. J Vasc Interv Radiol 25(10): 1595-1603, 2014. PMID: 25156647. DOI: 10.1016/j.jvir.2014.06.028

17 Wondergem M, Smits ML, Elschot M, de Jong HW, Verkooijen HM, van den Bosch MA, Nijsen JF and Lam MG: 99mTcmacroaggregated albumin poorly predicts the intrahepatic distribution of $90 \mathrm{Y}$ resin microspheres in hepatic radioembolization. J Nucl Med 54(8): 1294-1301, 2013. PMID: 23749996. DOI: 10.2967/jnumed.112.117614

18 Padia SA, Alessio A, Kwan SW, Lewis DH, Vaidya S and Minoshima S: Comparison of positron emission tomography and bremsstrahlung imaging to detect particle distribution in patients undergoing yttrium-90 radioembolization for large hepatocellular carcinomas or associated portal vein thrombosis. J Vasc Interv Radiol 24(8): 1147-1153, 2013. PMID: 23792126. DOI: 10.1016/j.jvir.2013.04.018

19 Chan KT, Alessio AM, Johnson GE, Vaidya S, Kwan SW, Monsky W, Wilson AE, Lewis DH and Padia SA: Prospective trial using internal pair-production positron emission tomography to establish the yttrium- 90 radioembolization dose required for response of hepatocellular carcinoma. Int J Radiat Oncol Biol Phys 101(2): 358-365, 2018. PMID: 29559288. DOI: 10.1016/j.jirobp.2018.01.116

Received March 5, 2021

Revised March 19, 2021

Accepted March 23, 2021 